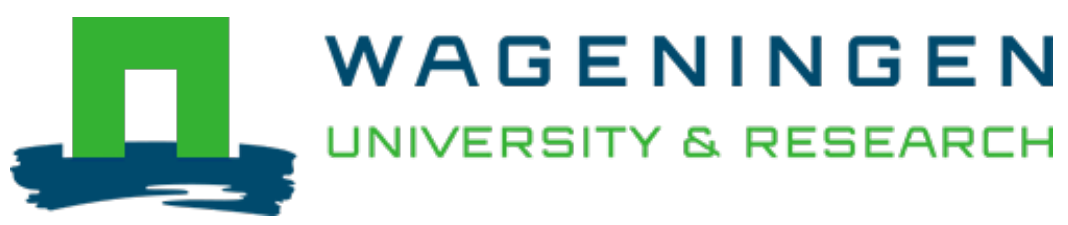

\title{
Quantifying the Feedback Between Rice Architecture, Physiology, and Microclimate Under Current and Future $\mathrm{CO}_{2}$ Conditions
}

\author{
Journal of Geophysical Research: Biogeosciences \\ Sikma, M.; Ikawa, H.; Heusinkveld, B.G.; Yoshimoto, M.; Hasegawa, T. et al \\ https://doi.org/10.1029/2019JG005452
}

This article is made publicly available in the institutional repository of Wageningen University and Research, under the terms of article $25 \mathrm{fa}$ of the Dutch Copyright Act, also known as the Amendment Taverne. This has been done with explicit consent by the author.

Article $25 \mathrm{fa}$ states that the author of a short scientific work funded either wholly or partially by Dutch public funds is entitled to make that work publicly available for no consideration following a reasonable period of time after the work was first published, provided that clear reference is made to the source of the first publication of the work.

This publication is distributed under The Association of Universities in the Netherlands (VSNU) 'Article $25 \mathrm{fa}$ implementation' project. In this project research outputs of researchers employed by Dutch Universities that comply with the legal requirements of Article 25fa of the Dutch Copyright Act are distributed online and free of cost or other barriers in institutional repositories. Research outputs are distributed six months after their first online publication in the original published version and with proper attribution to the source of the original publication.

You are permitted to download and use the publication for personal purposes. All rights remain with the author(s) and / or copyright owner(s) of this work. Any use of the publication or parts of it other than authorised under article $25 \mathrm{fa}$ of the Dutch Copyright act is prohibited. Wageningen University \& Research and the author(s) of this publication shall not be held responsible or liable for any damages resulting from your (re)use of this publication.

For questions regarding the public availability of this article please contact openscience.library@wur.nl 


\section{JGR Biogeosciences}

\author{
RESEARCH ARTICLE \\ 10.1029/2019JG005452 \\ Key Points: \\ - Plant architecture was identified as a \\ strong determinant of the relation \\ between plant physiology and \\ microclimate \\ - The combination of plant \\ architecture, physiology, and \\ microclimate had strong effects on \\ the surface energy balance
}

Supporting Information:

- Supporting Information S1

Correspondence to:

M. Sikma,

martin.sikma@wur.nl

Citation:

Sikma, M., Ikawa, H., Heusinkveld, B. G., Yoshimoto, M., Hasegawa, T., Groot Haar, L. T., et al. (2020). Quantifying the feedback between rice architecture, physiology, and microclimate under current and future $\mathrm{CO}_{2}$ conditions. Journal of Geophysical Research: Biogeosciences, 125, e2019JG005452. https://doi.org/10.1029/2019JG005452

Received 9 SEP 2019

Accepted 7 JAN 2020

Accepted article online 22 JAN 2020

c)2020. American Geophysical Union. All Rights Reserved.

\section{Quantifying the Feedback Between Rice Architecture, Physiology, and Microclimate Under Current and Future $\mathrm{CO}_{2}$ Conditions}

\author{
M. Sikma ${ }^{1,2}$ (D) H. Ikawa ${ }^{3}$ (D, B. G. Heusinkveld ${ }^{2}$, M. Yoshimoto ${ }^{3}$, T. Hasegawa 4 (D), \\ L. T. Groot Haar' ${ }^{2}$ N. P. R. Anten ${ }^{1}$, H. Nakamura ${ }^{5}$, J. Vilà-Guerau de Arellano' ${ }^{2}$ D, H. Sakai ${ }^{3}$, \\ T. Tokida ${ }^{3}$, Y. Usui ${ }^{6}$ iD, and J. B. Evers ${ }^{1}$ \\ ${ }^{1}$ Centre for Crop System Analysis, Wageningen University and Research, Wageningen, The Netherlands, ${ }^{2}$ Meteorology \\ and Air Quality Group, Wageningen University and Research, Wageningen, The Netherlands, ${ }^{3}$ Institute for Agro- \\ Environment Sciences, National Agriculture and Food Research Organization, Tsukuba, Japan, ${ }^{4}$ Tohoku Agricultural \\ Research Center, National Agriculture and Food Research Organization, Morioka, Japan, ${ }^{5}$ Taiyo Keiki Co. Ltd., Toda, \\ Japan, ${ }^{6}$ Hokkaido Agricultural Research Center, National Agriculture and Food Research Organization, Memuro, Japan
}

\section{Introduction}

All terrestrial biosphere processes and their interactions exist due to the stabilizing and damping response to solar radiation. From the industrial revolution onwards, human pressure on the biosphere system has dramatically increased, causing a destabilization of biosphere processes and their interactions, resulting in the average global temperature to rise (Höhne et al., 2011). In this respect, one might consider the influence of humans as an additional internal forcing to the biosphere system. The global anthropogenic environmental footprint is expected to increase in coming decades resulting from global population growth and increasing living standards (Hoekstra \& Wiedmann, 2014). Food demand will dramatically increase (e.g., Godfray et al., 2010; Tilman et al., 2011); anthropogenic and temperature-driven land-cover changes will occur (e.g., Pielke et al., 2016), which in turn will impact the local and regional radiation balance causing a change in weather patterns (e.g., de Kok et al., 2018; Mahmood et al., 2014). To anticipate on these changes, a detailed understanding of the consequences of these actions is of great importance, to be able to predict future biosphere changes and their consequences.

A key strategy towards increased food crop production involves increases in crop photosynthesis rates (e.g. Ort et al., 2015). Rice (Oryza sativa) is one of the three most important food crops (next to maize and wheat) and is a dominant landscape feature in many parts of the world. In addition, most of the rice in the world is grown in so-called paddy systems where soil is covered by water through much of the season. As such, it has a strong surface forcing on regional weather through its high-water usage. For example, Ikawa et al. (2017) revealed that evapotranspiration from Japanese irrigated rice fields amounted to $80-90 \%$ of the seasonal precipitation, which is around one third of the annual precipitation in Japan. 
Especially in developing regions that are strongly affected by climate change and that experience excessive population growth rates, improving crop productivity and yields can have vast consequences on the regional weather and climate through changes in the regional energy balance. Ultimately, this might affect regional crop productivity and influence yields in turn.

In the agricultural sciences, the impact of a future climate on crop yields is determined by analyzing current crop responses (Knutti et al., 2010; Li et al., 2015; Yin, 2013). Future yield projections are developed taking into account those current responses, but do not consider the nonlinear feedback of the crop to the changing atmosphere (e.g., Rial et al., 2004; their Figure 1). By so doing, weather is treated as long-term statistics. Local and regional variability is simplified to seasonal averaged or accumulated quantities of, for instance, temperature, precipitation, or radiation (e.g., Pielke et al., 2007). In this respect, local weather phenomena are explained by general climate characteristics of a specific region. This top-down approach eliminates the variability in crop responses to local weather (Pielke et al., 2007), which makes it difficult to determine their feedback on climate. To be able to assess that feedback, first, a bottom-up approach is needed, in which the effects of crops on their microenvironment are identified. In rice, differences in canopy structure and physiology between varieties have been documented to have an effect on canopy functioning (e.g., Chen et al., 2014). However, to which extent, these differences are caused by changes in canopy climate, and how this will change in future biosphere conditions is unclear. Therefore, in this study, we aimed to quantify the micrometeorological consequences of crop variety choice and their responses to rising $\mathrm{CO}_{2}$ levels. The microclimate of two distinct rice varieties, that strongly differ in both their architectural structure and physiological traits, was investigated for current and future (year 2050) $\mathrm{CO}_{2}$ levels. In this study, the microclimate is defined as the atmosphere directly affected by plant responses and structure (i.e., from 0 to $2 \mathrm{~m}$ above surface). The plants were grown embedded in irrigated rice paddies managed by Japanese farmers, to ensure that our findings reflect normal agronomic practices on the large scale in Japan. Future $\mathrm{CO}_{2}$ levels were mimicked by a Free-Air $\mathrm{CO}_{2}$ Enrichment (FACE) facility (Nakamura et al., 2012). We expected that these trait differences between these two varieties will result in different atmospheric interactions and that the effect of elevated $\mathrm{CO}_{2}$ on local microclimate will also differ between them.

\section{Materials and Methods}

\subsection{Site Description and Crop Characteristics}

In order to quantify the impact of plant architectural and physiological effects on the microclimate, an experiment was conducted at the Tsukuba FACE facility in Tsukubamirai, Ibaraki Prefecture, Japan $\left(35^{\circ} 58^{\prime} \mathrm{N}\right.$, $139^{\circ} 60^{\prime} \mathrm{E}$; $10 \mathrm{~m}$ a.s.l.; soil type: fluvisol) between May and September 2015 (Nakamura et al., 2012). The site represented typical Japanese flood-irrigated rice (Oryza sativa) fields under humid subtropical conditions. The wet season was in June and September, while July and August temperatures were relatively dry with much sunshine. Four blocks were allocated in the rice fields, with each block containing one octagonal FACE plot and one ambient replicate (i.e., control plot) both with a diameter of $17 \mathrm{~m}$ (i.e., $\sim 240 \mathrm{~m}^{2}$ ). Pure $\mathrm{CO}_{2}$ was fumigated from the peripheries of the octagonal rings by two horizontal tubes to ensure an average target elevation of $200 \mu \mathrm{mol} \mathrm{mol}^{-1}$ during daylight conditions compared to ambient conditions. The plots were separated by at least $70 \mathrm{~m}$ to minimize cross-contamination. During the months July and August, the average $\mathrm{CO}_{2}$ concentration $\left(\left[\mathrm{CO}_{2}\right]\right) \pm$ day-to-day standard deviation was $384 \pm 12.5 \mu \mathrm{mol} \mathrm{mol}^{-1}$ in the ambient control with $578 \pm 18.5 \mu \mathrm{mol} \mathrm{mol}{ }^{-1}$ in FACE. The latter reflects the expected global $\mathrm{CO}_{2}$ level in 2050 based on the RCP4.5 IPCC scenario (IPCC, 2014). For further details regarding the Tsukuba FACE system, see Nakamura et al. (2012) and Hasegawa et al. (2016).

Within the plots, two distinct rice varieties were grown: Koshihikari, a commonly grown Japanese japonica variety, and Takanari, a high yielding indica variety. Both Takanari and Koshihikari were transplanted by hand at a spacing of $30 \mathrm{~cm}$ (between rows) $\times 15 \mathrm{~cm}$ (along the row) with a resultant density of 22.2 hills per $\mathrm{m}^{2}$ and grown in rows with a North-South orientation in an area of at least $3 \mathrm{~m}^{2}$ (Figure 1). Takanari has been identified as a potential future candidate to increase rice grain yield in Japan. Compared to Koshihikari, Takanari maintains higher levels of (leaf) photosynthesis (e.g., Chen et al., 2014) and exhibits higher stomatal conductance (30-40\%) (Chen et al., 2014; Hasegawa et al., 2013; Ikawa et al., 2018), resulting in an increase in yields levels of up to $21 \%$ (Hasegawa et al., 2013). Furthermore, Takanari is able to achieve higher productivity in elevated $\left[\mathrm{CO}_{2}\right]$ conditions, due to its high sink capacity and photosynthetic activity, 


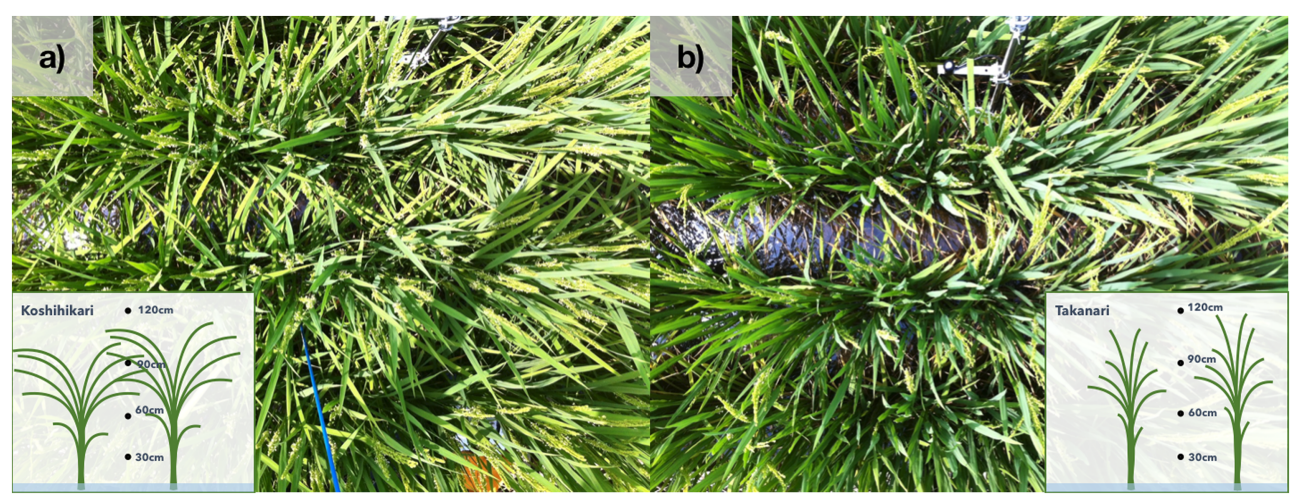

Figure 1. A top-down photograph of the (a) Koshihikari and (b) Takanari canopy during early-grain filling stage. Takanari has more erect leaves resulting in a more open canopy compared to Koshihikari, as visualized in the illustrative insets. The points represent the measurement heights for air temperature, relatively humidity, $\mathrm{CO}_{2}$ concentration and photosynthetic active radiation.

and showed greater yield enhancement under elevated $\mathrm{CO}_{2}$ compared to Koshihikari (Hasegawa et al., 2013; Hasegawa et al., 2019; Nakano et al., 2017; Zhang et al., 2015). Leaf area index (LAI) of both varieties ranging from approximately 4 to $5 \mathrm{~m}^{2} \mathrm{~m}^{-2}$ in July to August 2015, and a previous study from our FACE system reported LAI did not differ between Koshihikari and Takanari, despite a large difference in in-canopy light interception (Muryono et al., 2017).

\subsection{Microclimate Measurements}

From June to September 2015, detailed in- and above-canopy microclimate measurements were performed in one elevated $\left[\mathrm{CO}_{2}\right]$ and one ambient plot. In the middle of each Takanari and Koshihikari plot (see Figure S8 in the supporting information), air temperature ( $\mathrm{T}_{\mathrm{a}}$ ), relative humidity (RX-350TH, As One Co., Japan), and photosynthetically active radiation (PAR; Apogee SQ-110; data logger: Decagon ECH2O EM50) were measured every minute at four heights $\left(30,60,90\right.$, and $120 \mathrm{~cm}$ above soil surface). $\left[\mathrm{CO}_{2}\right]$ was also measured (LI-820, LI-COR INC., U.S.A.) at those four heights, although only one height was analyzed per minute, resulting in one $\left[\mathrm{CO}_{2}\right]$ measurement per $4 \mathrm{~min}$ per height. Furthermore, due to limited availability of $\left[\mathrm{CO}_{2}\right]$ profilers, the sensors were moved between Koshihikari and Takanari weekly. To assess whether this weekly measurement lag had consequences on our results, we have additionally normalized the in-canopy data with the above canopy $\left[\mathrm{CO}_{2}\right]$ measurements (Figure S4). This normalization data allows the relative incanopy comparison between Koshihikari and Takanari. Water temperature $\left(\mathrm{T}_{\mathrm{w}}\right)$ sensors (Platinum resistance thermometer Pt100) were located at the bottom of ponding water (i.e., on the soil surface) in each plot and variety and measured continuously throughout the season every $10 \mathrm{~min}$. The water depth was relatively constant between 5 and $10 \mathrm{~cm}$. At the North-Western (downwind) border of both ambient and elevated $\mathrm{CO}_{2}$ plots, an eddy-covariance system (IRGASON Campbell U.S.A) was installed $15 \mathrm{~cm}$ above canopy top, measuring $\mathrm{CO}_{2}$ and $\mathrm{H}_{2} \mathrm{O}$, sonic temperature, and 3D wind at $50 \mathrm{~Hz}$. Raw IRGASON data were processed to halfhourly fluxes with the software package EddyPro (LI-COR INC., U.S.A.). The IRGASON was manually raised with increasing canopy height every week such that it was consistently $15 \mathrm{~cm}$ above the canopy. Due to the relatively small experimental area, it was not feasible to perform separate flux measurements for both Takanari and Koshihikari in ambient and FACE conditions. As a consequence, our flux results are an aggregation of responses mainly from the two varieties (note this only applies to the IRGASON, all other measurements were done separately per variety), but the FACE and ambient plots were measured separately. Nevertheless, to our knowledge, surface energy flux measurements in a FACE setup have not been performed, although they have been estimated using modelling approaches (Ikawa et al., 2018; Yoshimoto et al., 2005). Because the surface flux measurements were performed close to canopy top due to the limited size of each experimental plot, data sampling was performed at high frequency (50 $\mathrm{Hz})$ to resolve relatively small turbulence. By doing so, we were able to get an understanding of the in-canopy to above-canopy interactions occurring in the ambient and FACE setup. Footprint analysis showed that nearly all of our measurements originate within $5 \mathrm{~m}$ from the IRGASON device (Figure S5; Matthes et al., 2014, 


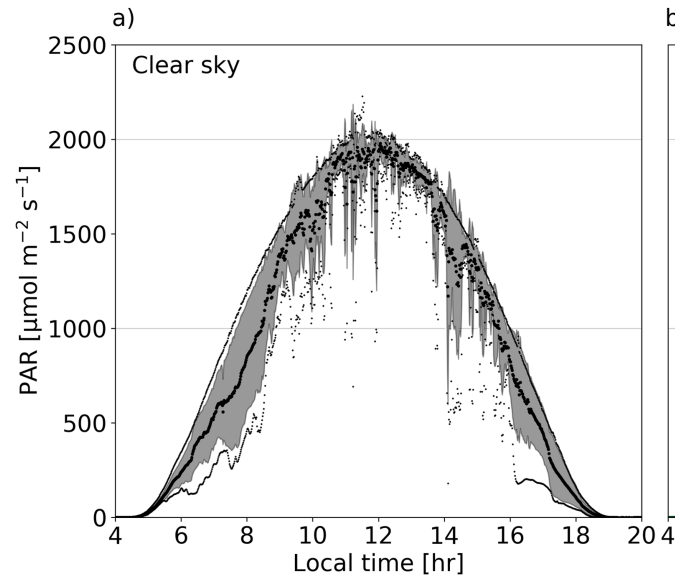

b)

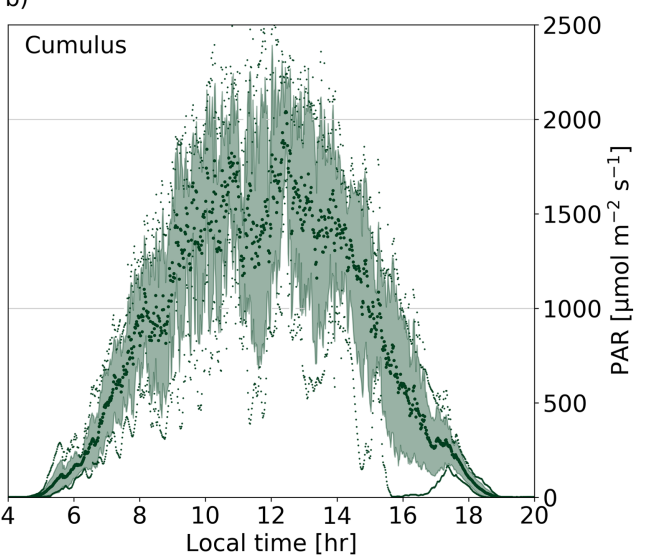

Figure 2. The diurnal evolution of above canopy photosynthetically active radiation (PAR) data aggregated and clustered based on radiative conditions, as described in the methodology. In total, six clear sky days-26, 27 July; 1, 2, 5, 7 August—and seven partly cloudy days-24, 25, 30 July; 10, 11, 16, 19 August—were chosen for analysis. In (a), the clear sky situations are shown, while (b) shows the partly cloudy (i.e., cumulus) situations. Thick scatter points denote the average radiation, while the small scatter points indicate the minimum and maximum radiation on those days.

The colored spread shows the standard deviation of the clustered data.

Ikawa et al., 2015). Cospectral analysis revealed minimal flux loss at higher frequencies. Figure S6 shows that a stable flux averaging interval is achieved within $100 \mathrm{~s}$. In Figure S7, we show that the IRGASON was capable of capturing the high frequencies, as it follows the theoretical $-4 / 3$ slope well. Furthermore, it also shows that most eddies have a timescale of around $10 \mathrm{~s}$, which is around $2 / 3$ of the total flux as shown in the Ogive (Figure S6; Oncley et al., 1996). Canopy temperature $\left(\mathrm{T}_{\mathrm{c}}\right)$ was measured every minute by an infrared radiative thermometer (MI-230, Apogee Instruments Inc., U.S.A.) under an angle of $45^{\circ}$ pointing South (to ensure no contamination by the water temperature) from mid-July to mid-September (i.e., harvest).

\subsection{Data Selection}

In-canopy rice, microclimate conditions are strongly affected by the regional atmosphere, the vegetative state, and canopy architecture. To ensure a fair microclimate comparison between Koshihikari and Takanari, variations in those influencers need to be limited. Following our data (Sikma, 2019), we found the period of mid-July till mid-August to be most suitable for a significant and representative evaluation: From mid-July onwards, Koshihikari and Takanari had reached their maximum height of 91 and $86 \mathrm{~cm}$, respectively (i.e., no changing canopy height dependency in our data) and were close to flowering and part of the season where green LAI and associated photosynthesis are maximal. Furthermore, during this period, variations in weather conditions were relatively minor, and many clear and partly cloudy days occurred. Therefore, as a next step, the data were clustered based on radiative conditions (i.e., clear sky, partly cloudy) and aggregated as shown in Figure 2. In total, six clear sky days [26, 27 July; 1, 2, 5, 7 August] and seven partly cloudy days [24, 25, 30 July; 10, 11, 16, 19 August] were chosen for analysis. The data have been additionally checked on wind direction and speed, to ensure no cross-contamination from FACE to ambient site occurred. In the remainder of this study, all microclimate data are aggregated based on these two categories of radiative conditions. In the following two sections, we first focus solely on a clear sky weather regime as in these conditions the plant-atmosphere relations are pronounced. This is followed by a shorter description of the partly cloudy weather regime.

\section{Results and Discussion}

\subsection{In-Canopy Microclimate in Current Conditions}

The different vertical structures of Takanari and Koshihikari (Figure 1) resulted in distinct in-canopy radiative conditions, as apparent from the temporal distribution of PAR (Figures 3a-3c). Especially at $30 \mathrm{~cm}$ above ground level (AGL), PAR levels were low throughout the day, with the exception when the sun was 

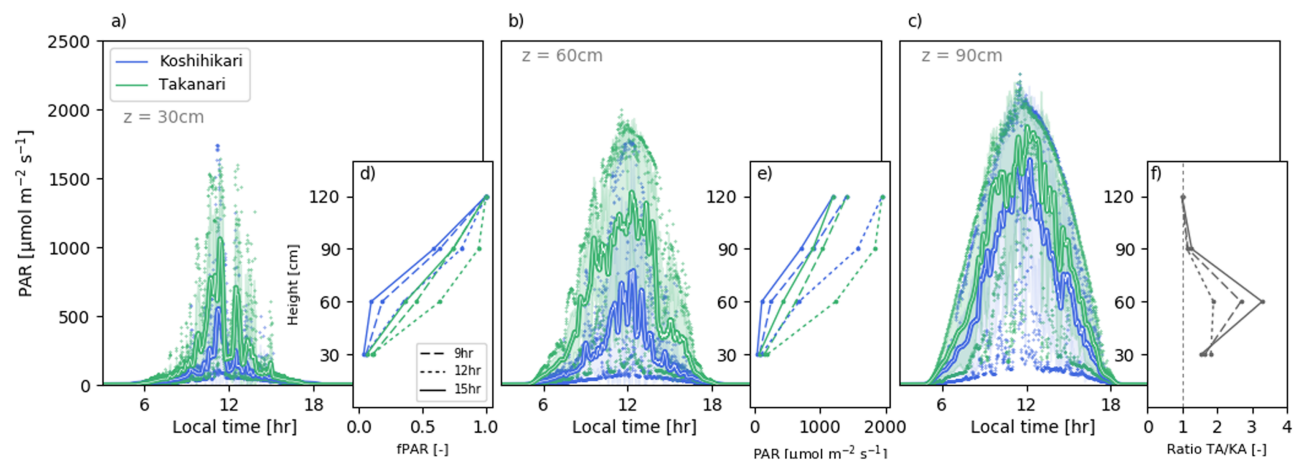

Figure 3. The diurnal evolution of in-canopy photosynthetically active radiation (PAR) during clear sky days (26, 27 July; 1, 2, 5, 7 August) of Koshihikari (blue) and Takanari (green) at (a) $30 \mathrm{~cm}$, (b) $60 \mathrm{~cm}$, and (c) $90 \mathrm{~cm}$ above soil. Note: (d), (e), and (f) are stand-contained figures showing the PAR relation over the four measurements heights (i.e., 30, 60, 90, $120 \mathrm{~cm}$ ). (d) The PAR in-canopy profiles normalized with above canopy PAR for 9, 12, and 15 LT (15 min averaged). (e) The absolute values of (d). (f) The ratio Takanari ambient (TA) vs Koshihikari ambient (KA) is visualized over three time stamps. The average height of Koshihikari was $91 \mathrm{~cm}$, while Takanari was slightly shorter with $86 \mathrm{~cm}$.

at zenith. Furthermore, Takanari showed more sun spikes than Koshihikari, resulting from its more open canopy structure, despite LAI being similar (ranging from 4 to $5 \mathrm{~m}^{2} \mathrm{~m}^{-2}$ in July and August 2015). Light levels declined much more steeply in the canopy of Koshihikari than in the canopy of Takanari. At $60 \mathrm{~cm}$ AGL-around 2/3 of the canopy height—-the largest differences were found between the varieties with many sun flecks from leaf blocking for Koshihikari, while the open structure of Takanari resulted in up to three times higher levels of PAR at this depth. Close to canopy top (90 cm AGL), the difference in PAR between both varieties decreased. Takanari on average intercepted less radiation and PAR at this height was closer to the maximum available PAR, while sun flecks were more common in Koshihikari. Overall, higher levels and a less steep extinction of PAR when moving from the top to the bottom of the canopy were found in Takanari (Figures $3 \mathrm{~d}$ and $3 \mathrm{e}$ ).

The in-canopy microclimate is influenced by both the plant architectural structure as well as its physiological response to environment. With Takanari having an open canopy structure and higher transpiration levels as compared to Koshihikari (Chen et al., 2014), we expected vast differences in the diurnal in-canopy microclimate. In the morning, the open canopy structure of Takanari allowed for increased radiative penetration as well as convective mixing, but for Koshihikari, this mixing was hampered by the more closed canopy of this variety. Resulting from a reduced radiative in-canopy interception, daytime in-canopy temperatures of Koshihikari were lower compared to Takanari (Figure 4a). However, lower $\left(\sim 0.5^{\circ} \mathrm{C}\right)$ leaf

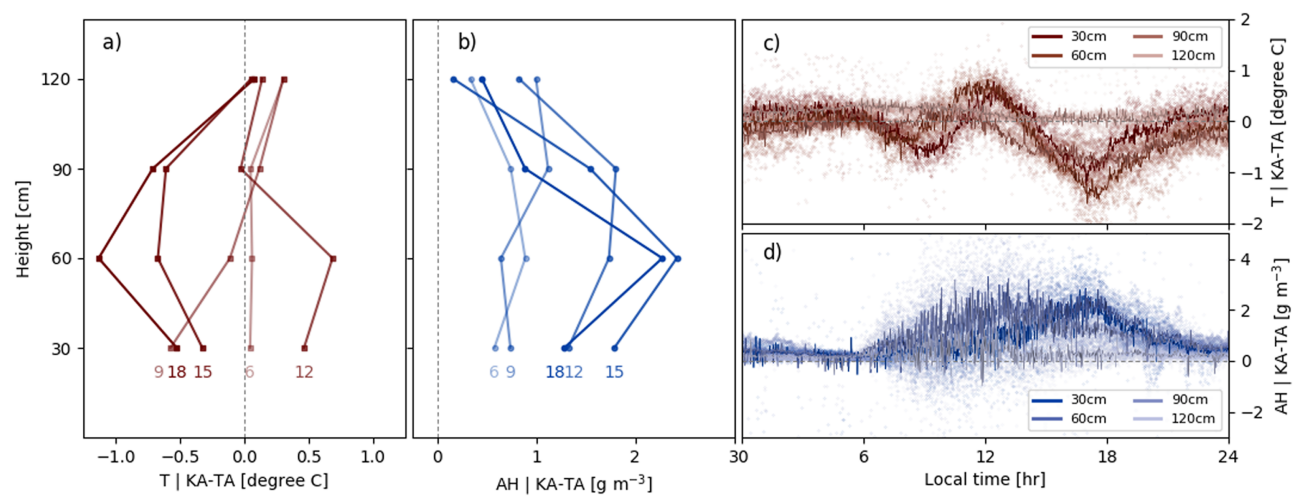

Figure 4. The diurnal evolution of the difference in in-canopy temperature (T; red) and absolute humidity (AH; blue) between Koshihikari ambient (KA) and Takanari ambient (TA) in clear sky conditions (26, 27 July; 1, 2, 5, 7 August). In (a) and (b), the differences in the diurnal evolution in vertical profiles between Koshihikari ambient and Takanari ambient are shown for temperature and absolute humidity, respectively. In c) and d), the diurnal differences between KA and TA for all heights are shown. Scatter points are retrieved from actual measurements, while the lines represent a moving average (15 $\mathrm{min})$. 

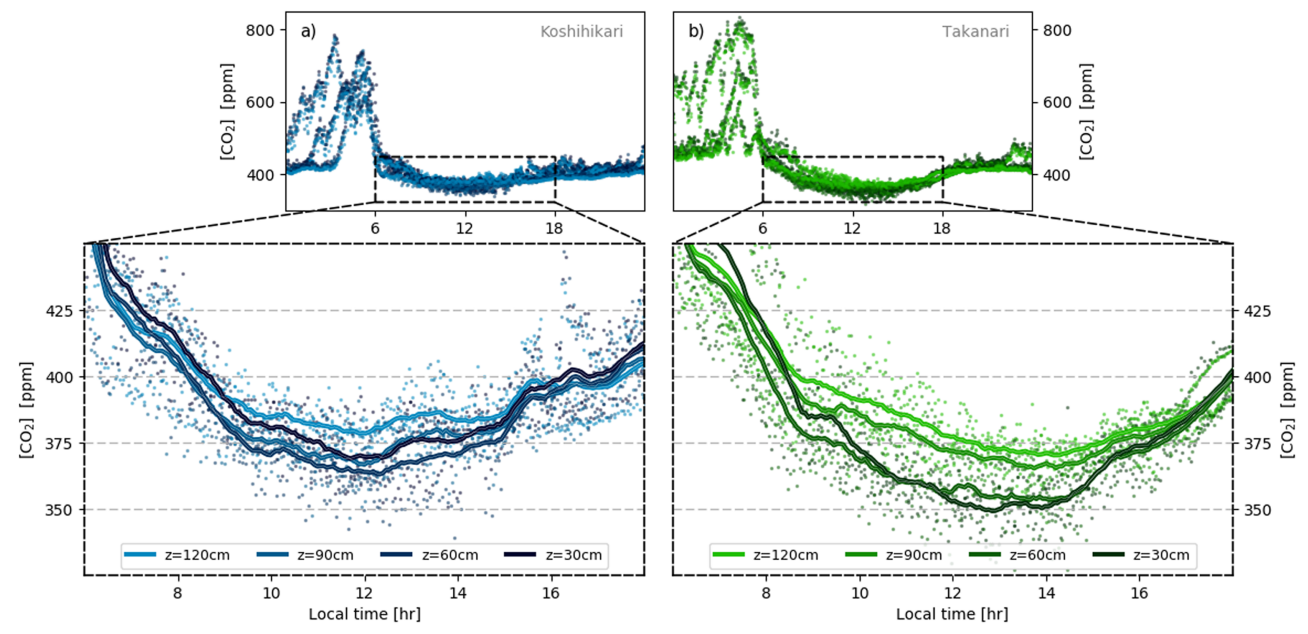

Figure 5. Diurnal evolution of $\mathrm{CO}_{2}$ concentration $\left[\mathrm{CO}_{2}\right]$ for Koshihikari (left) and Takanari (right) at four measurement heights at ambient site. The lower panels show a zoom over the daylight period (i.e., 6 to $18 \mathrm{LT}$ ). Scatter points represent all data, while the lines show a moving average of $15 \mathrm{~min}$. Measurements of Takanari were performed the 26, 27 July and 7 August; Koshihikari at 1, 2, 5 August.

temperatures were found in Takanari, which likely resulted from the higher stomatal conductance of Takanari and its associated higher evaporative cooling rates known for this variety (Ikawa et al., 2018). Paradoxically, this did not result in a more humid canopy (Figure 4b). In the case of Koshihikari, the relatively closed canopy likely hampered the vertical exchange of air, which may have resulted in a build-up of in-canopy moisture by evapotranspiration. Accumulation of in-canopy moisture most likely did not occur as much in Takanari due to its open canopy structure, resulting in small above- and in-canopy differences in absolute humidity.

A strong interplay between canopy structure and solar angle was observed in the diurnal evolution of the temperature and absolute humidity (Figures $4 \mathrm{c}$ and $4 \mathrm{~d}$ ). With the North-South row orientation and the sun at a Southerly position during zenith (i.e., 12 local time), more direct radiation was able to reach the lower in-canopy leaves and stems, as well as the soil and water surface, causing the vertical in-canopy temperature differences to decrease (Figures 4a and 4c). In Koshihikari, the warming effect was more pronounced at noon due to a higher canopy temperature that raises in-canopy temperatures compared to Takanari. During the afternoon, increased water temperature [data available in Sikma, 2019] increased evaporation, resulting in humid Koshihikari in-canopy conditions (Figure 4d). However, due to an increase in in-canopy air temperature of Takanari, which was likely the result of warm and dry air advection (explained in more detail later), absolute humidity levels were reduced. Due to the relatively closed canopy top, Koshihikari was less affected, hence the higher absolute humidity levels.

Strong differences were visible in the diurnal uptake rates of $\mathrm{CO}_{2}$ inferred by $\mathrm{CO}_{2}$ concentration $\left(\left[\mathrm{CO}_{2}\right]\right)$ profile measurements (Figure 5). During night time, $\left[\mathrm{CO}_{2}\right]$ increased as a result of plant respiration and the absence of wind (peaks observed in Figure 5), causing thermal stratification by cooling above the canopy. At sunrise, turbulent mixing started, and photosynthesis activated, reducing the $\left[\mathrm{CO}_{2}\right]$. Our results show the strong effect of canopy structure (i.e., mixing) and leaf physiology on the in-canopy $\left[\mathrm{CO}_{2}\right]$ (zoomed-in sections in Figure 5). Takanari likely had higher photosynthetic activity (i.e., uptake rates) compared to Koshihikari, with Takanari having nearly similar $\left[\mathrm{CO}_{2}\right]$ at 30 and $60 \mathrm{~cm}$. This infers the higher $\mathrm{CO}_{2}$ assimilation of Takanari than Koshihikari at these levels (Chen et al., 2014). From $90 \mathrm{~cm}$ upwards, atmospheric mixing leads to increased $\mathrm{CO}_{2}$ levels, although the youngest (i.e., active) leaves were found around $90 \mathrm{~cm}$ during this growing stage. Although Koshihikari is less photosynthetically active $(\sim-20 \%$ compared to Takanari, Chen et al., 2014), reduced vertical mixing allowed for relatively low $\left[\mathrm{CO}_{2}\right]$ at $90 \mathrm{~cm}$, which were comparable with values found at $30 \mathrm{~cm}$. Note that the reason for low $\mathrm{CO}_{2}$ levels at both 90 and $30 \mathrm{~cm}$ are likely different: Photosynthetic uptake rates at $30 \mathrm{~cm}$ were reduced, while atmospheric mixing diluted the uptake signal at $90 \mathrm{~cm}$. Minimum levels of $\left[\mathrm{CO}_{2}\right]$ were found at $60 \mathrm{~cm}$, where the impact of atmospheric exchange was less, resulting in a strong influence of higher $\mathrm{CO}_{2}$ uptake rates. 


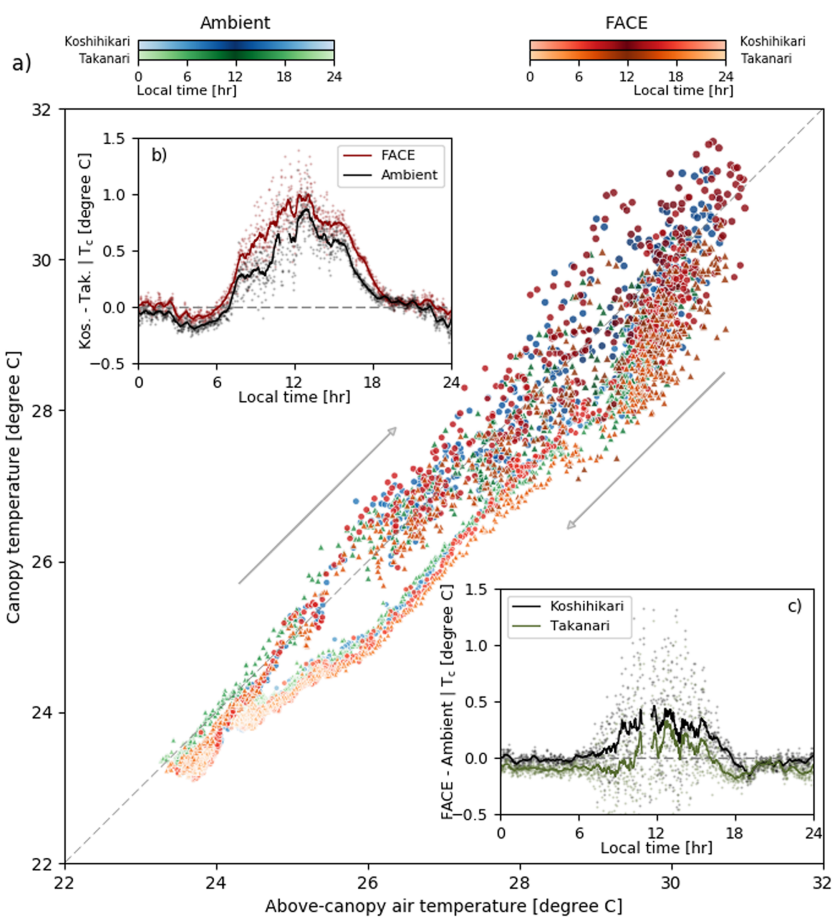

Figure 6. Relation between above-canopy air temperature and canopy temperature (measured under an angle of $45^{\circ}$ ) during clear sky days (26, 27 July; 1, 2, 5, 7 August). Warm colors represent FACE, while the cold colors indicate ambient. The main figure shows the diurnal evolution for both Koshihikari (circles) and Takanari (triangles). The upper inset shows the diurnal difference between Koshihikari and Takanari for FACE (red) and ambient (black) situations. The lower inset shows the effect of FACE on Koshihikari (black) and Takanari (green). For both insets, scatter points represent data, while the lines show an 15 min average. Note that there is some data missing, hence the gap in the moving average.

\subsection{The Effects of Increasing $\mathrm{CO}_{2}$ on the Microclimate}

Increasing atmospheric levels of $\mathrm{CO}_{2}$ cause the difference in partial pressure between plant intercellular and atmospheric levels to increase (Ainsworth \& Rogers, 2007; Strain, 1985). As a consequence, the plants stomatal aperture narrows, with the subsequent effect that leaf temperatures start to rise due to decreased transpirational cooling. Especially during the flowering and grain-filling period of rice, this process might have consequences on grain quality and yield, as increased air temperatures can cause spikelet sterility (e.g., Satake \& Yoshida, 1978) and exacerbate heat-induced damage in grain appearance quality (Usui et al., 2016).

The diurnal cycle in near-surface air temperature was closely related to the canopy temperature. For both varieties, a near-linear increase in both canopy and above-canopy air temperature was found during morning (Figure 6a). Especially Koshihikari reached high canopy and air temperatures up to $\sim 31^{\circ} \mathrm{C}$, while Takanari stabilized around $\sim 30^{\circ} \mathrm{C}$ (circles above one-to-one line in Figure 6a). In elevated $\left[\mathrm{CO}_{2}\right]$, Koshihikari experienced stronger warming effects than Takanari. Normally during the afternoon, a sea breeze initiated advection of warm and dry air from a neighboring city, which delayed the decline in air temperature as would be expected from the daily-cycle in canopy temperature and radiation. Due to reduced wind speeds, the role of advection diminished during night time.

The high stomatal conductance, thus transpirational cooling of Takanari (e.g., Ikawa et al., 2018), becomes evident in the diurnal course of canopy temperature (Figure 6b). Throughout the day, Takanari maintains a lower canopy temperature, while the canopy temperature of Koshihikari showed a strong increase (Figure 6b). Furthermore, an increase in $\left[\mathrm{CO}_{2}\right]$ to $\sim 580 \mu \mathrm{mol} \mathrm{mol}{ }^{-1}$ caused the average day-time canopy temperature to increase, but this effect was larger in Koshihikari $\left(\sim 0.5^{\circ} \mathrm{C}\right)$ than in Takanari $\left(\sim 0.3^{\circ} \mathrm{C}\right.$; Figure $\left.6 \mathrm{c}\right)$. On warm days, this increase even went up to periods of $\sim 1^{\circ} \mathrm{C}$ for both varieties.

These warming effects of $\mathrm{CO} 2$ elevation can have negative impacts on yields, for example, through acceleration of seed development or occurrence of spike sterility (e.g., Julia \& Dingkuhn, 2013). Long-term FACE data analysis showed that yield enhancement by elevated $\left[\mathrm{CO}_{2}\right]$ (fertilization) was reduced by the increase in temperature during the grain filling (Hasegawa et al., 2016), and grain quality was severely reduced by elevated $\left[\mathrm{CO}_{2}\right]$ notably in hot years (Usui et al., 2016). Our results suggest that a shift to Takanari might be a good alternative to cope with near-future climate change as the $\mathrm{CO}_{2}$ induced warming is smaller in this variety. This view is supported by the fact that appearance quality of Takanari was reported to be much less affected by elevated $\left[\mathrm{CO}_{2}\right]$ than that of Koshihikari (Zhang et al., 2015).

The interplay between plant architecture and physiology strongly determined the daily cycle of microclimate. Our results show strong sensitivity to measurement height in crop microclimate (Figure 7). This may be an important aspect for determining and measuring the crop microclimate.

Due to atmospheric mixing, the impact from an elevation in $\left[\mathrm{CO}_{2}\right]$ to above-canopy air temperature was damped, resulting in similar diurnal patterns of above-canopy (i.e., $120 \mathrm{~cm} \mathrm{AGL)} \mathrm{air} \mathrm{temperature} \mathrm{for} \mathrm{both}$ varieties (Figure $7 \mathrm{a})$. The impact of $\left[\mathrm{CO}_{2}\right]$ was more pronounced near the canopy top ( 90 $\left.\mathrm{cm}\right)$, where stomatal closure resulted in a greater FACE-induced warming in Koshihikari than in Takanari. Moving into the canopy, the plant structure started to play a role (Figures 7b-7d). The open architecture of Takanari allowed mixing, while this mixing was hampered for Koshihikari due to its closed canopy top. Especially in the morning, in-canopy air, temperatures were increased in elevated $\left[\mathrm{CO}_{2}\right]$ conditions for Koshihikari, while this was less pronounced for Takanari (Figures 7c and 7d). This suggests that Takanari maintained high stomatal conductance and associated transpirational cooling compared to Koshihikari in elevated $\left[\mathrm{CO}_{2}\right]$. With the solar angle at zenith during noon, more direct radiation 

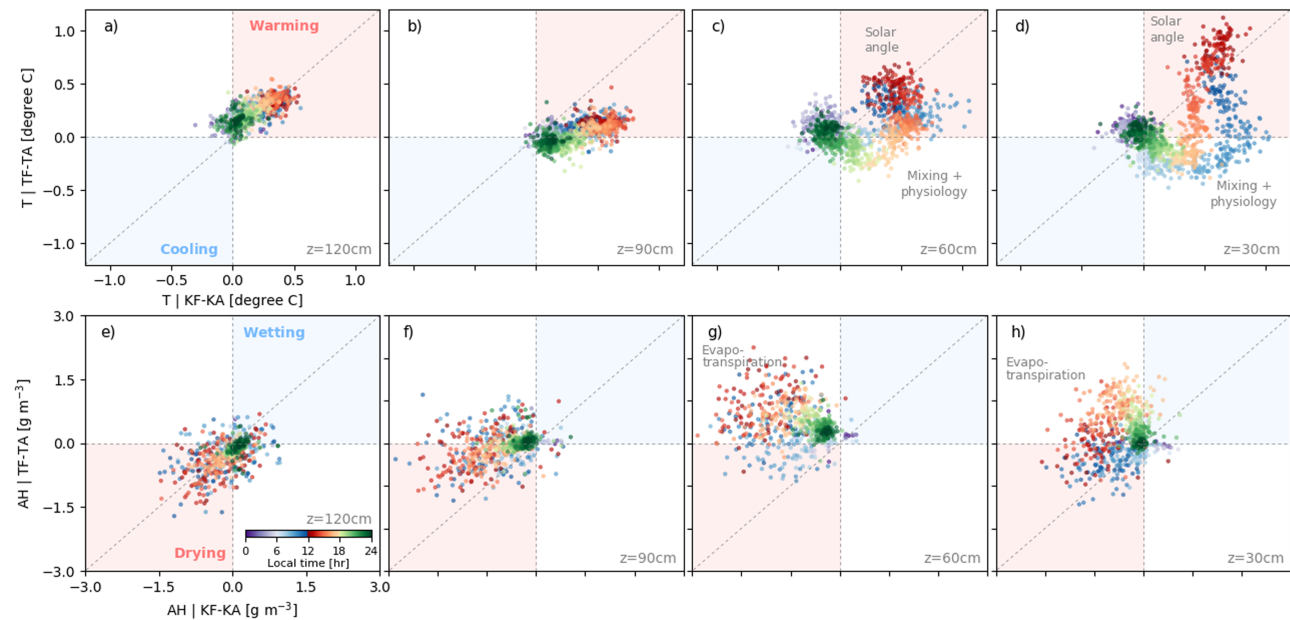

Figure 7. The effects of FACE on the diurnal evolution of temperature (T; upper panels) and absolute humidity (AH; lower panels) for Koshihikari (x-axis) and Takanari (y-axis) at all measurement heights in clear sky conditions (26, 27 July; 1, 2, 5, 7 August). The color denotes the time of day. The average height of Koshihikari was $91 \mathrm{~cm}$, while Takanari was slightly shorter with $86 \mathrm{~cm}$.

penetrated the canopy and caused in-canopy air temperatures to rise, resulting in similar warming for both varieties. In the afternoon, a stronger increase in air temperatures was found in Koshihikari again, while in-canopy, humidity levels were lower due to reduced transpiration rates (Figures $7 \mathrm{e}-7 \mathrm{~h}$ ). Especially close to the water surface at $30 \mathrm{~cm}$, humidity levels increased faster during the afternoon in Takanari as a consequence of the increased water temperature (thus increased evaporation) and the high transpiration rates (Figure $7 \mathrm{~h}$ ).

Our surface energy balance measurements show the integrated effects of plant architecture, physiology, and microclimate (Figure 8). The distribution of energy over irrigated rice paddies is unique compared to other land surfaces. In the morning, the sensible heat flux increases as a consequence of an increased canopy temperature (Figure 6), which causes the air temperature to rise. In FACE conditions, the rise in air temperature was accelerated due to stomatal responses to $\mathrm{CO}_{2}$. Following from our in-canopy temperature and humidity
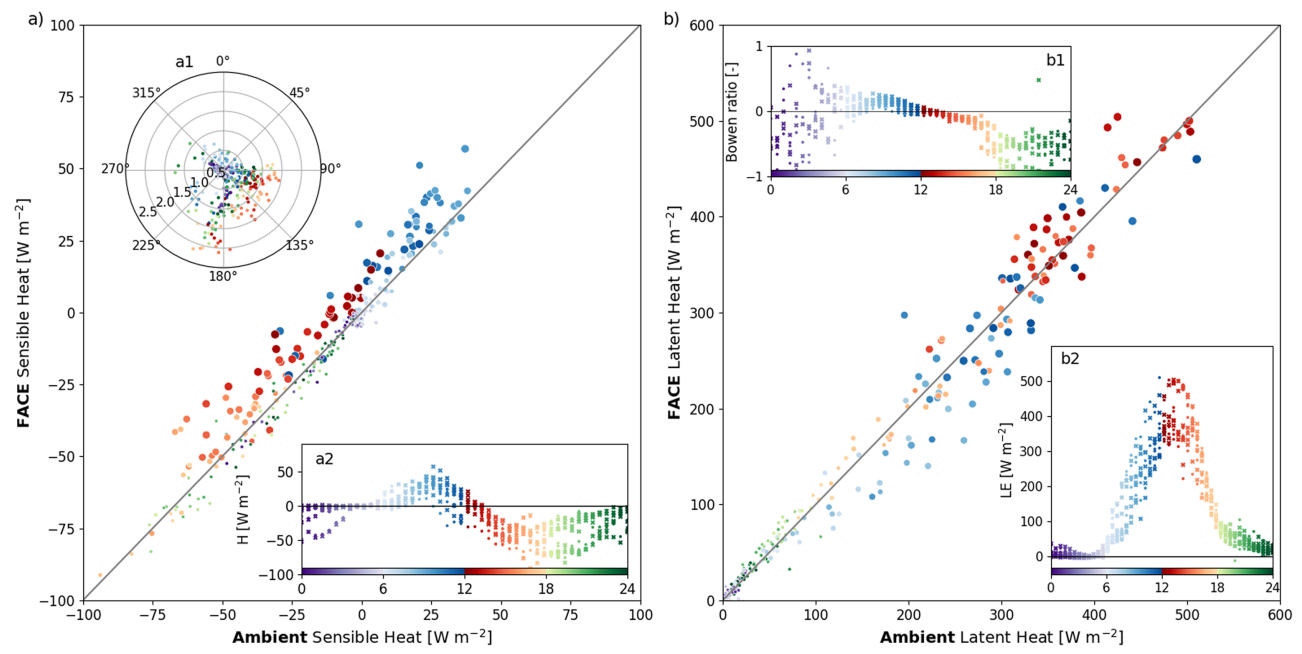

Figure 8. Surface flux relationship of (a) the sensible heat (H) and (b) latent heat (LE) are shown for ambient (x-axis) and FACE (y-axis) during clear sky conditions (26, 27 July; 1, 2, 5, 7 August). The circle size is determined by the PAR levels (Figure 2a). The insets in a show wind direction and speed in $\mathrm{m} \mathrm{s}^{-1}$ (a1) and the diurnal evolution in sensible heat flux (a2) for ambient (circles) and FACE (crosses) conditions. In b, the diurnal evolution in Bowen ratio (b1) and latent heat flux (b2) are shown. Ambient is represented with circles, while FACE is visualized with crosses. In all plots, the color denotes the time of day. 


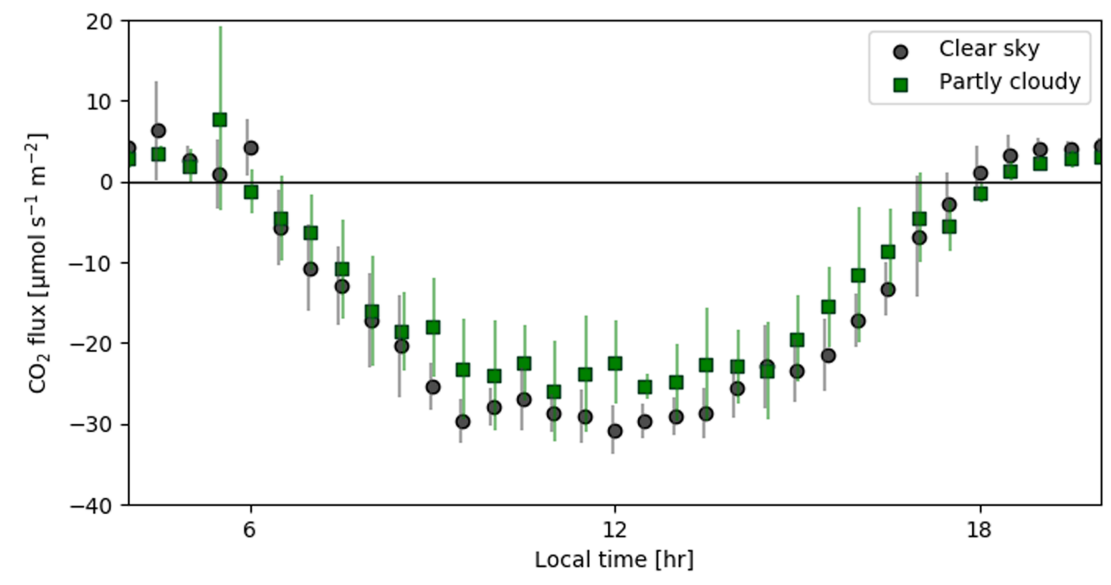

Figure 9. Diurnal evolution of the $30 \mathrm{~min} \mathrm{CO}_{2}$ fluxes for clear sky (black; 26, $27 \mathrm{July} ; 1,2,5,7$ August) and partly cloudy (green; 24, 25, 30 July; 10, 11, 16, 19 August) weather regimes in ambient conditions. Sunrise is around 6 LT, while sun set is around 18 LT. The points represent the mean flux over the aggregated data (see Figure 2), and the associated error bars are visualized. Note that the error bars for both cases have been shifted slightly to avoid overlap.

measurements, we ascribe this effect mainly to Koshihikari. Especially in the morning when the wind speed was low (i.e., low mixing), strong effects of the narrowing in stomatal aperture were found in the latent heat flux (Figure 8b). Those effects became less pronounced during noon. One of the reasons could be midday stomatal closure that reduced the signal in latent heat flux differences between FACE and ambient, as well as an increased water temperature and enhanced evaporation rates.

In the afternoon ( 14 LT), the atmospheric synoptic condition allowed for the initiation of a daily seabreeze circulation, causing the wind speeds and subsequently atmospheric mixing to increase. As a consequence of the fractured land-scape in Japan, meaning that rice fields and cities are alternated, warm and dry-air was advected from a nearby city to our experimental site. As a result, the sensible heat flux became strongly negative (i.e., oasis effect), while the latent heat fluxes were maximum due to the relatively dry air.

When the sun set around $~ 18 \mathrm{LT}$, the latent heat flux was still positive likely because evaporation was maintained. Furthermore, our results show that the sea-breeze weakened and wind speeds decreased (Figure 8a1). However, since the wind direction was still from the city, the sensible heat flux remained negative, although its magnitude slowly decreased towards zero with decreasing wind speed (Figure 8a).

\subsection{Effects of Shallow Clouds on the Plant-Atmosphere Interactions}

In the results described above, the focus was on clear-sky weather conditions close to flowering period. In the analysis, clear differences in diurnal patterns in the relations between plants architecture, physiology, and microclimate emerged. However, this approach could cause a biased view on the plant-atmosphere interactions solely caused by the direct component of radiation. For example, a seasonal study on the effect of clearsky and partly clouded sky regimes on the uptake of $\mathrm{CO}_{2}$ showed stronger uptake rates during partly clouded skies in a mixed forest site (Freedman et al., 2001), which was a result of an enhanced diffuse radiation component. It is well-known that the diffuse radiation component has the ability to penetrate more efficiently into the canopy, potentially causing photosynthesis levels to rise depending on conditions (Min \& Wang, 2008; Pedruzo-Bagazgoitia et al., 2017). To understand the sensitivity of our results to the direct-diffuse proportion, we aggregated the data during the same time period for partly clouded sky regimes (Figure $2 \mathrm{~b}$ ). By comparing the maximum clear-sky and partly clouded diurnal PAR (Figure 2), it became clear that during partly clouded skies, the radiation levels could increase with a maximum of 10 to $20 \%$ due to cloud reflection and scattering, although the average PAR was lower compared to clear-sky situations (Figure 2b). However, this did not increase the $\mathrm{CO}_{2}$ uptake rates (Figure 9). Apart from the lower in-canopy temperature and moisture levels, no large differences were found in the relative in-canopy profiles of temperature, humidity, and radiation (Figures $\mathrm{S} 1-\mathrm{S} 3$ ). 


\subsection{Putting our Results in Perspective}

The results presented in this study show the intrinsic relation between rice architecture, physiology, and microclimate. Measurements were performed on distinct rice varieties that strongly differ in both architecture and physiology. Our results show the importance of canopy architectural differences on the surface fluxes that might affect land-atmosphere processes. While many modeling studies consider vertical distribution of in-canopy radiation (de Pury \& Farquhar, 1997), air temperature and $\mathrm{CO}_{2}$ are often assumed to be constant throughout the canopy in a terrestrial model (e.g., Zhang et al., 2014 and refs therein). However, with the current advancement in computational power and improved understanding of modelling concepts, it is expected that multilayer canopy approaches including radiative transfer and calculations of the profiles of the state variables will become a more common approach (e.g., Xu et al., 2014). Therefore, detailed incanopy measurements are becoming essential to move forward.

Our results are based on an aggregation of days based on sky regimes (i.e., clear sky, partly cloudy), which makes our results more consistent and robust than when a single "golden" day approach would have been followed. However, since our measurements were only performed in one region (i.e., Kanto area, Japan), extrapolation of our results to other regions needs to be done with caution. For example, the FACE facility used in this study had a strong consistent daily synoptic (i.e., regional weather) cycle. At around 14 LT, a sea-breeze facilitated enhanced atmospheric mixing and the advection of dry and warm air from urban areas, which altered the plant-atmosphere interaction and caused an enhanced evaporative flux.

Our FACE results are only capturing the plant physiological response to increasing levels of $\mathrm{CO}_{2}$. Temperature and humidity levels also act as an additional external forcing to the plant-atmosphere responses, which are not taken into account in this study. Furthermore, as a consequence to an altered atmospheric composition (e.g., humidity levels), the light quality and radiation distribution will likely change. As a result, the partitioning into diffuse and direct radiation will be affected, with vast effects on the plant-atmosphere interaction. Moreover, with the expectation that urban areas expand, the influence of dry and warm air advection will likely increase in the future, impacting the rice microclimate.

Our results show that moving from Koshihikari to a rice variety like Takanari as the primary variety in Japanese rice production would result in strong effects on crop microclimate potentially leading to higher production under elevated $\mathrm{CO}_{2}$ conditions. Although the current experimental setup did not allow for surface energy balance measurements of solely Koshihikari or Takanari, our in-canopy vertical profiles clearly showed a distinct microclimate and subsequent surface forcing to the overlying atmosphere. Especially the high photosynthetic capacity of Takanari results in a damped response to atmospheric warming when $\mathrm{CO}_{2}$ levels rise, as the high stomatal conductance and transpiration associated with this higher photosynthesis of Takanari resulted in a larger evaporative cooling effect compared to Koshihikari. The difference in canopy temperature between the two varieties $\left(\sim 0.8^{\circ} \mathrm{C}\right)$ is greater than that reported in our recent model study ( $\sim .5^{\circ}$ C; Figure 7-c in Ikawa et al., 2018), which assumed the same canopy architecture between the two varieties. This emphasizes the importance of considering differences in architectural effects between varieties in future modeling studies. Additionally, we showed that a variety that produces closed canopies such as Koshihikari may suffer from heat-induced spikelet sterility under typical climate change scenarios. Spikelet sterility occurs when a plant fails to set grain due to abiotic stresses (e.g., Satake \& Yoshida, 1978). Many processes that affect grain setting are temperature driven and vulnerable to heat (i.e., $35-40^{\circ}$ C; Hasegawa et al., 2011). Even an exposure of 1 hour is sufficient to induce sterility (Jagadish et al., 2007). Current crop models account for sterility by simulating the diurnal patterns in temperature, humidity, transpirational cooling, and flowering time (e.g., van Oort et al., 2014 and refs therein). Some models predict variables for standardized atmospheres (e.g., sinusoidal temperature behavior), while the actual atmosphere is prone to fluctuations (Figures $4 \mathrm{c}$ and $4 \mathrm{~d}$ ), and effects of fluctuating environment must be considered in future (Tanaka et al., 2019). Progress in the recent years shows that modelling the panicle temperature instead of air temperature leads to more accurate results (e.g., Yoshimoto et al., 2011). Following from our results, we suggest to take into account plant architecture, solar angle, and suggest to parameterize turbulent mixing (i.e., function of wind speed). By so doing, we expect a more solid evaluation on the risk of spikelet sterility in future climates. 


\section{Conclusion}

The plant-atmosphere interaction is strongly influenced by both plant physiology and architecture. In this study, two contrasting rice varieties were investigated in ambient and elevated $\mathrm{CO}_{2}$ environments: Takanari, a high-yielding indica variety with an open canopy structure, and Koshihikari, a standard japonica variety with a more closed canopy top. Detailed microclimate measurements were performed, and the results were related and quantified to plant physiological and architectural characteristics. Our data are optimal for validating models related to detailed plant-atmosphere interactions in current and future climates.

Our ambient setup showed a strong diurnal interplay between solar angle (i.e., row orientation), canopy structure, plant physiology, and daily recurring synoptic weather (i.e., sea breeze circulation), of which the latter initiated warm and dry air advection from urban areas. An open-canopy structure allowed for enhanced atmospheric mixing and increased in-canopy radiation levels, thereby increasing in-canopy temperature and reducing the absolute humidity. In ambient conditions, Takanari had a drier and warmer in-canopy environment throughout the day, except at noon. Especially in the afternoon, Koshihikari experienced higher levels of absolute humidity (up to $2 \mathrm{~g} / \mathrm{m}^{3}$ ), which was caused by closed canopy structure, allowing for a build-up in moisture.

In an elevated $\mathrm{CO}_{2}$ environment (i.e., $\mathrm{FACE}$ ), different results were found, where Takanari's in-canopy absolute humidity was higher, and air temperature levels were lower compared to Koshihikari. This was caused by a strong physiological effect in combination with the likely enhanced evaporation rates from the water surface.

To conclude, plant architecture has a strong impact on the daily microclimate and drives the interaction between plant physiology and boundary-layer processes through vertical exchange. Both physiology and architecture differ considerably both between and as shown here within crop species. Under elevated $\mathrm{CO}_{2}$ conditions, an open-canopy rice variety such as Takanari will result in higher production while at the same time reducing the risk of spikelet sterility.

\section{References}

We thank team members of the Tsukuba FACE at the Institute for Agro-Environmental Sciences, NARO for their help in the field and laboratory measurements, with special thanks to Hitomi Wakatsuki. This work was supported in part by the Ministry of Agriculture, Forestry and Fisheries, Japan, through a research project entitled "Development of technologies for mitigation and adaptation to climate change in agriculture, forestry and fisheries" and the Netherlands Organisation for Scientific Research (NWO; grant no. 823.01.012). Raw and processed data used in this manuscript are stored on a public repository that can be accessed through http://doi.org/ 10.4121/uuid:625cf57e-aaf0-4be4-bfb0f2f $48 \mathrm{e} 6 \mathrm{c} 78 \mathrm{fb}$.
Ainsworth, E. A., \& Rogers, A. (2007). The response of photosynthesis and stomatal conductance to rising [CO2]: Mechanisms and environmental interactions. Plant, Cell and Environment, 30, 258-270. https://doi.org/10.1111/j.1365-3040.2007.01641.x

Chen, C. P., Sakai, H., Tokida, T., Usui, Y., Nakamura, H., \& Hasegawa, T. (2014). Do the rich always become richer? Characterizing the leaf physiological response of the high-yielding rice cultivar takanari to Free-Air CO2 Enrichment. Plant \& Cell Physiology, 55(2), 381-391. https://doi.org/10.1093/pcp/pcu009

Freedman, J. M., Fitzjarrald, D. R., Moore, K. E., \& Sakai, R. K. (2001). Boundary layer clouds and vegetation-atmosphere feedbacks. Journal of Climate, 14, 180-197. https://doi.org/10.1175/1520-0442(2001)013<0180:BLCAVA>2.0.CO;2

Godfray, H. C. J., Beddington, J. R., Crute, I. R., Haddad, L., Lawrence, D., Muir, J. F., et al. (2010). Food Security: The challenge of feeding 9 billion people. Science, 327(5967), 812-818. https://doi.org/10.1126/science.1185383

Hasegawa, T., Ishimaru, T., Kondo, M., Kuwagata, T., Yoshimoto, M., \& Fukuoka, M. (2011). Spikelet sterility of rice observed in the record hot summer of 2007 and the factors associated with its variation. Journal of Agricultural Meteorology, 67, 225-232. https://doi.org/ 10.2480/agrmet.67.4.3

Hasegawa, T., Sakai, H., Tokida, T., Nakamura, H., Zhu, C., Usui, Y., et al. (2013). Rice cultivar responses to elevated $\mathrm{CO}_{2}$ at two free-air $\mathrm{CO}_{2}$ enrichment (FACE) sites in Japan. Functional Plant Biology, 40(2), 148-159. https://doi.org/10.1071/FP12357

Hasegawa, T., Sakai, H., Tokida, T., Usui, Y., Nakamura, H., Wakatsuki, H., et al. (2019). A High-Yielding Rice Cultivar "Takanari" Shows No N Constraints on $\mathrm{CO}_{2}$ Fertilization. Frontiers in Plant Science, 10, 361. https://doi.org/10.3389/fpls.2019.00361

Hasegawa, T., Sakai, H., Tokida, T., Usui, Y., Yoshimoto, M., Fukuoka, M., et al. (2016). Rice Free-Air Carbon Dioxide Enrichment studies to improve assessment of climate change effects on rice agriculture. In J. L. Hatfield \& D. Fleisher (Eds.), Improving Modelling Tools to Assess Climate Change Effects on Crop Response, Advances in Agricultural Systems Modeling (Vol. 7, pp. 1-24). Madison, USA: American Society of Agronomy, Crop Science Society of America, and Soil Science Society of America, Inc. https://doi.org/10.2134/ advagricsystmodel7.2014.0015

Hoekstra, A. Y., \& Wiedmann, T. O. (2014). Humanity's unsustainable environmental footprint. Science, 344, $1114-1117$.

Höhne, N., Blum, H., Fuglestvedt, J., Skeie, R. B., Kurosawa, A., Hu, G., et al. (2011). Contributions of individual countries' emissions to climate change and their uncertainty. Climatic Change, 106(3), 359-391. https://doi.org/10.1007/s10584-010-9930-6

Ikawa, H., Chen, C. P., Sikma, M., Yoshimoto, M., Sakai, H., Tokida, T., et al. (2018). Increasing canopy photosynthesis in rice can be achieved without a large increase in water use-A model based on free-air $\mathrm{CO}_{2}$ enrichment. Global Change Biology, 24(3), 1321-1341. https://doi.org/10.1111/gcb.13981

Ikawa, H., Nakai, T., Busey, R. C., Kim, Y., Kobayashi, H., Nagai, S., et al. (2015). Understory $\mathrm{CO}_{2}$, sensible heat, and latent heat fluxes in a black spruce forest in interior Alaska. Agricultural and Forest Meteorology, 214-215, 80-90. https://doi.org/10.1016/j. agrformet.2015.08.247

Ikawa, H., Ono, K., Mano, M., Kobayashi, K., Takimoto, T., Kuwagata, T., \& Miyata, A. (2017). Evapotranspiration in a rice paddy field over 13 crop years. Journal of Agricultural Meteorology, 73, 109-118. https://doi.org/10.2480/agrmet.D-16-00011

IPCC (2014). Climate Change 2014: Synthesis Report. Contribution of Working Groups I, II and III to the Fifth Assessment Report of the Intergovernmental Panel on Climate Change [Core Writing Team, R.K. Pachauri and L.A. Meyer (eds.)]. IPCC, Geneva, Switzerland, $151 \mathrm{pp}$. 
Jagadish, S. V. K., Craufurd, P. Q., \& Wheeler, T. R. (2007). High temperature stress and spikelet fertility in rice (Oryza sativa L.). Journal of Experimental Botany, 58, 1627-1635. https://doi.org/10.1093/jxb/erm003

Julia, C., \& Dingkuhn, M. (2013). Predicting temperature induced sterility of rice spikelets requires simulation of crop-generated microclimate. European Journal of Agronomy. Elsevier B.V., 49, 50-60. https://doi.org/10.1016/j.eja.2013.03.006

Knutti, R., Furrer, R., Tebaldi, C., Cermak, J., \& Meehl, G. A. (2010). Challenges in combining projections from multiple climate models Journal of Climate, 23, 2739-2758. https://doi.org/10.1175/2009JCLI3361.1

de Kok, R. J., Tuinenburg, O. A., Bonekamp, P. N. J., \& Immerzeel, W. W. (2018). Irrigation as a potential driver for anomalous glacier behavior in high mountain Asia. Geophysical Research Letters, 45, 2047-2054. https://doi.org/10.1002/2017GL076158

Li, T., Hasegawa, T., Yin, X., Zhu, Y., Boote, K., Adam, M., et al. (2015). Uncertainties in predicting rice yield by current crop models under a wide range of climatic conditions. Global Change Biology, 21(3), 1328-1341. https://doi.org/10.1111/gcb.12758

Mahmood, R., Pielke, R. A. Sr., Hubbard, K. G., Niyogi, D., Dirmeyer, P. A., McAlpine, C., et al. (2014). Land cover changes and their biogeophysical effects on climate. International Journal of Climatology, 34(4), 929-953. https://doi.org/10.1002/joc.3736

Matthes, J. H., Sturtevant, C., Verfaillie, J., Knox, S., \& Baldocchi, D. (2014). Parsing the variability in $\mathrm{CH}_{4}$ flux at a spatially heterogeneous wetland: Integrating multiple eddy covariance towers with high-resolution flux footprint analysis: parsing variability in wetland $\mathrm{CH}_{4}$ flux. Journal of Geophysical Research: Biogeosciences, 119. https://doi.org/10.1002/2014JG002642

Min, Q., \& Wang, S. (2008). Clouds modulate terrestrial carbon uptake in a midlatitude hardwood forest. Geophysical Research Letters, 35 , L02406. https://doi.org/10.1029/2007GL032398

Muryono, M., Chen, C. P., Sakai, H., Tokida, T., Hasegawa, T., Usui, Y., et al. (2017). Nitrogen distribution in leaf canopies of high-yielding rice cultivar Takanari. Crop Science, 57(4), 2080-2088. https://doi.org/10.2135/cropsci2016.07.0589

Nakamura, H., Tokida, T., Yoshimoto, M., Sakai, H., Fukuoka, M., \& Hasegawa, T. (2012). Performance of the enlarged Rice FACE system using pure CO2 installed in Tsukuba, Japan. Journal of Agricultural Meteorology, 68, 15-23. https://doi.org/10.2480/ agrmet.68.1.2

Nakano, H., Yoshinaga, S., Takai, T., Arai-Sanoh, Y., Kondo, K., Yamamoto, T., et al. (2017). Quantitative trait loci for large sink capacity enhance rice grain yield under free-air $\mathrm{CO}_{2}$ enrichment conditions. Scientific Reports, 7, 1827. https://doi.org/10.1038/ s41598-017-01690-8

Oncley, S. P., Friehe, C. A., Larue, J. C., Businger, J. A., Itsweire, E. C., \& Chang, S. S. (1996). Surface-layer fluxes, profiles, and turbulence measurements over uniform terrain under near-neutral conditions. Journal of the Atmospheric Sciences, 53, 1029-1044. https://doi.org/ 10.1175/1520-0469(1996)053<1029:SLFPAT>2.0.CO;2

van Oort, P. A. J., Saito, K., Zwart, S. J., \& Shrestha, S. (2014). A simple model for simulating heat induced sterility in rice as a function of flowering time and transpirational cooling. Field Crops Research, 156, 303-312. https://doi.org/10.1016/j.fcr.2013.11.007

Ort, D. R., Merchant, S. S., Alric, J., Barkan, A., Blankenship, R. E., Bock, R., et al. (2015). Redesigning photosynthesis to sustainable meet global food and bioenergy demand. Proceedings of the National Academy of Sciences of the United States of America, 112(28), 8529-8536. www.pnas.org/cgi/doi/10.1073/pnas.1424031112

Pedruzo-Bagazgoitia, X., Ouwersloot, H. G., Sikma, M., van Heerwaarden, C. C., Jacobs, C. M. J., \& Vilà-Guerau de Arellano, J. (2017). Direct and diffuse radiation in the shallow cumulus-vegetation system: Enhanced and decreased evapotranspiration regimes. Journal of Hydrometeorology, 18, 1731-1748. https://doi.org/10.1175/JHM-D-16-0279.1

Pielke, R. A. Sr., Adegoke, J. O., Chase, T. N., Marshall, C. H., Matsui, T., \& Niyogi, D. (2007). A new paradigm for assessing the role of agriculture in the climate system and in climate change. Agricultural and Forest Meteorology, 142, 234-254. https://doi.org/10.1016/j. agrformet.2006.06.012

Pielke, R. A. Sr., Mahmood, R., \& McAlpine, C. (2016). Land's complex role in climate change. Physics Today, 69(11), 40-46. https://doi.org/ 10.1063/PT.3.3364

de Pury, D. G. G., \& Farquhar, G. D. (1997). Simple scaling of photosynthesis from leaves to canopies without the errors of big-leaf models. Plant, Cell and Environment, 20, 537-557. https://doi.org/10.1111/j.1365-3040.1997.00094.x

Rial, J. A., Pielke Sr, R. A., Beniston, M., Claussen, M., Canadell, J., Cox, P., et al. (2004). Nonlinearities, feedbacks and critical thresholds within the earth's climate system. Climate Change, 65(1/2), 11-38. https://doi.org/10.1023/B:CLIM.0000037493.89489.3f

Satake, T., \& Yoshida, S. (1978). High temperature-induced sterility in indica rices at flowering. Japanese Journal of Crop Science, 47, 6-17. https://doi.org/10.1626/jcs.47.6

Sikma, M. (2019). Supplementary data of "Japan FACE 2015 experiment". 4TU.Centre for Research Data. Dataset. https://doi.org/10.4121/ uuid:625cf57e-aaf0-4be4-bfb0-f2f48e6c78fb

Strain, B. R. (1985). Background on the response of vegetation to atmospheric carbon dioxide enrichment. In B. R. Strain \& J. D. Cure (Eds.), Direct effects of increasing carbon dioxide on vegetation (Chap. 1, pp. 1-10). Washington, DC: United States Department of Energy. https://www.osti.gov/servlets/purl/6134866

Tanaka, Y., Adachi, S., \& Yamori, W. (2019). Natural genetic variation of the photosynthetic induction response to fluctuating light environment. Current Opinion in Plant Biology, 49, 52-59. https://doi.org/10.1016/j.pbi.2019.04.010

Tilman, D., Balzer, C., Hill, J., \& Befort, B. L. (2011). Global food demand and the sustainable intensification of agriculture. Proc. Nat. Amer Soc., 108, 20,260-20,264. www.pnas.org/cgi/doi/10.1073/pnas.1116437108

Usui, Y., Sakai, H., Tokida, T., Nakamura, H., Nakagawa, H., \& Hasegawa, T. (2016). Rice grain yield and quality responses to free-air $\mathrm{CO}_{2}$ enrichment combined with soil and water warming. Global Change Biology, 22(3), 1256-1270. https://doi.org/10.1111/gcb.13128

Xu, L., Pyles, R. D., Paw U, K. T., Chen, S. H., \& Monier, E. (2014). Coupling the high-complexity land surface model ACASA to the mesoscale model WRF. Geoscientific Model Development, 7(6), 2917-2932. https://doi.org/10.5194/gmd-7-2917-2014

Yin, X. (2013). Improving ecophysiological simulation models to predict the impact of elevated atmospheric $\mathrm{CO}_{2}$ concentration on crop productivity. Annals of Botany, 112, 465-475. https://doi.org/10.1093/aob/mct016

Yoshimoto, M., Fukuoka, M., Hasegawa, T., Utsumi, M., Ishigooka, Y., \& Kuwagata, T. (2011). Integrated micrometeorology model for panicle and canopy temperature ( $\mathrm{IM}^{2} \mathrm{PACT}$ ) for rice heat stress studies under climate change. Journal of Agricultural Meteorology, 67(4), 233-247. https://doi.org/10.2480/agrmet.67.4.8

Yoshimoto, M., Oue, H., \& Kobayashi, K. (2005). Energy balance and water use efficiency of rice canopies under free-air CO2 enrichment. Agricultural and Forest Meteorology, 133, 226-246. https://doi.org/10.1016/j.agrformet.2005.09.010

Zhang, G., Sakai, H., Usui, Y., Tokida, T., Nakamura, H., Zhu, C., et al. (2015). Grain growth of different rice cultivars under elevated $\mathrm{CO} 2$ concentrations affects yield and quality. Field Crops Research, 179, 72-80. https://doi.org/10.1016/j.fcr.2015.04.006

Zhang, L., Hu, Z., Fan, J., Zhou, D., \& Tang, F. (2014). A meta-analysis of the canopy light extinction coefficient in terrestrial ecosystems. Frontiers in Earth Science, 8(4), 599-609. https://doi.org/10.1007/s11707-014-0446-7 